\section{First record of Resseliella salvadorae (Rao) (Diptera: Cecidomyiidae) and its parasitoid from stem and leaf galls of Salvadora persica L. Sudan}

\author{
E.M. Moawia ${ }^{1}$, S.I. Ensaf ${ }^{2}$ \& R.M. Sharma ${ }^{3}$ \\ 1,2 Shambat Research Station, Agricultural Research \\ Corporation, P.O.Box 30, Khartoum North, Sudan 1111 \\ ${ }^{3}$ Zoological Survey of India, Western Regional Centre, \\ Vidhyanagar, Akurdi, Pune, Maharashtra 411044, India \\ Email: ${ }^{1}$ elaiderous3@yahoo.com, ${ }^{2}$ ensafmohamed1@gmail.com, \\ ${ }^{3}$ rmsharma53@yahoo.in (corresponding author)
}

Salvadora persica L. (Salvadoraceae), commonly known as Tooth Brush Tree, Mustard Tree or Salt Bush, is an evergreen shrub. Its leaves are oblongelliptic to almost circular, light to dark green, rather fleshy. It is widespread and native to many countries including India (locally known as Pilu or Jhak) and Sudan (locally known as Arak). It is a xerophytic plant, occupying desert floodplains and also common in river and stream bank vegetation. It is highly salt tolerant thus very useful in improvement of salt affected black soils, eco-restoration of the degraded saline wastelands. It can be used for sand dune reclamation.

Date of publication (online): 26 October 2012

Date of publication (print): 26 October 2012

ISSN 0974-7907 (online) | 0974-7893 (print)

Editor: S.S. Udiker

Manuscript details:

Ms \# 02872

Received 13 July 2011

Final received 10 August 2012

Finally accepted 12 September 2012

Citation: Moawia, E.M., S.I. Ensaf \& R.M. Sharma (2012). First record of Resseliella salvadorae (Rao) (Diptera: Cecidomyiidae) and its parasitoid from stem and leaf galls of Salvadora persica L. Sudan Journal of Threatened Taxa 4(13): 3215-3217.

Copyright: ( E.M. Moawia, S.I. Ensaf \& R.M. Sharma 2012. Creative Commons Attribution 3.0 Unported License. JoTT allows unrestricted use of this article in any medium for non-profit purposes, reproduction and distribution by providing adequate credit to the authors and the source of publication.

Acknowledgements: RMS thanks the Director, Zoological Survey of India, Kolkata for permitting him to carry out the studies and providing facilities. We are also thankful to Dr. (Mrs) K. Rajmohana, Scientist-C, Zoological Survey of India, Kozhikode for identifying the parasites.

ZooBank urn:Isid:zoobank.org:pub:E59E630E-09C1-409D-9E0902F2F5D135E0

OPEN ACCESS | FREE DOWNLOAD
It is also a medicinal plant and almost all the plant parts have been found to be medically important and possess pharmaceutical applications. The plant does not suffer from any major pests and diseases (Rao et al. 2003), however, its leaves and stems are subjected to gall formation by Resseliella (=Thomasiniana) salvadorae (Rao) (Diptera: Cecidomyiidae) reported from India (Rao 1951, 1971; Mani 1973; Sharma et al. 2003; Sharma 2009). Platygaster salvadorae Rao (Hymenoptera: Platygastridae: Platygastrinae) has been recorded parasitizing the gall maker (Mani 1973). The present report is a first record of galls, gall causing insect and its parasitoid on Salvadora persica L. from Khartoum State, Sudan.

\section{Materials and Methods}

Galls were noticed on stem and leaves of coppice of Salvadora persica in the vicinity of Shambat Research Station, and National Botanic Garden in Khartoum North, Sudan (15031'N \& 32035'E) during the month of October 2010. The gall formed areas of the plant were covered with finely perforated plastic bags to monitor the emergence of the gall maker and its parasitoids.

Galls, cross sections through the galls, insect adults emerged from the galls were examined under a digital microscope (Digital Blue QX5 computer microscope, (www.digiblue.com) and their images captured.

\section{Results and Discussion}

Leaf gall (Image 1 a-f): Epi-hypophyllous, spherical, mostly adjacent to the midrib (Image 1a). Larval chamber cylindrical, more than one chamber per gall containing single larva inside (Image 1c).

Stem gall: Subglobose, ovoid or fusiform, glabrous, grayish in color, hard, woody, indehiscent, persistent swellings of tender branches, 5-10 $\mathrm{mm}$ long and $5 \mathrm{~mm}$ thick (Image 1d). One to six chambers per gall were noticed (Image 1e). As many as 13 galls were produced along $10 \mathrm{~cm}$ length and $5 \mathrm{~mm}$ thick stem. Larva seen in one of the stem gall chamber (Image 1f).

Gall midge larva and adult are shown in Image 2 a-d. Initially, hymenopterous parasitoids (platygastrid) (Image $3 \mathrm{a}-\mathrm{d}$ ) were recovered from the perforated plastic bags followed by adult gall midges (Images 2c, 

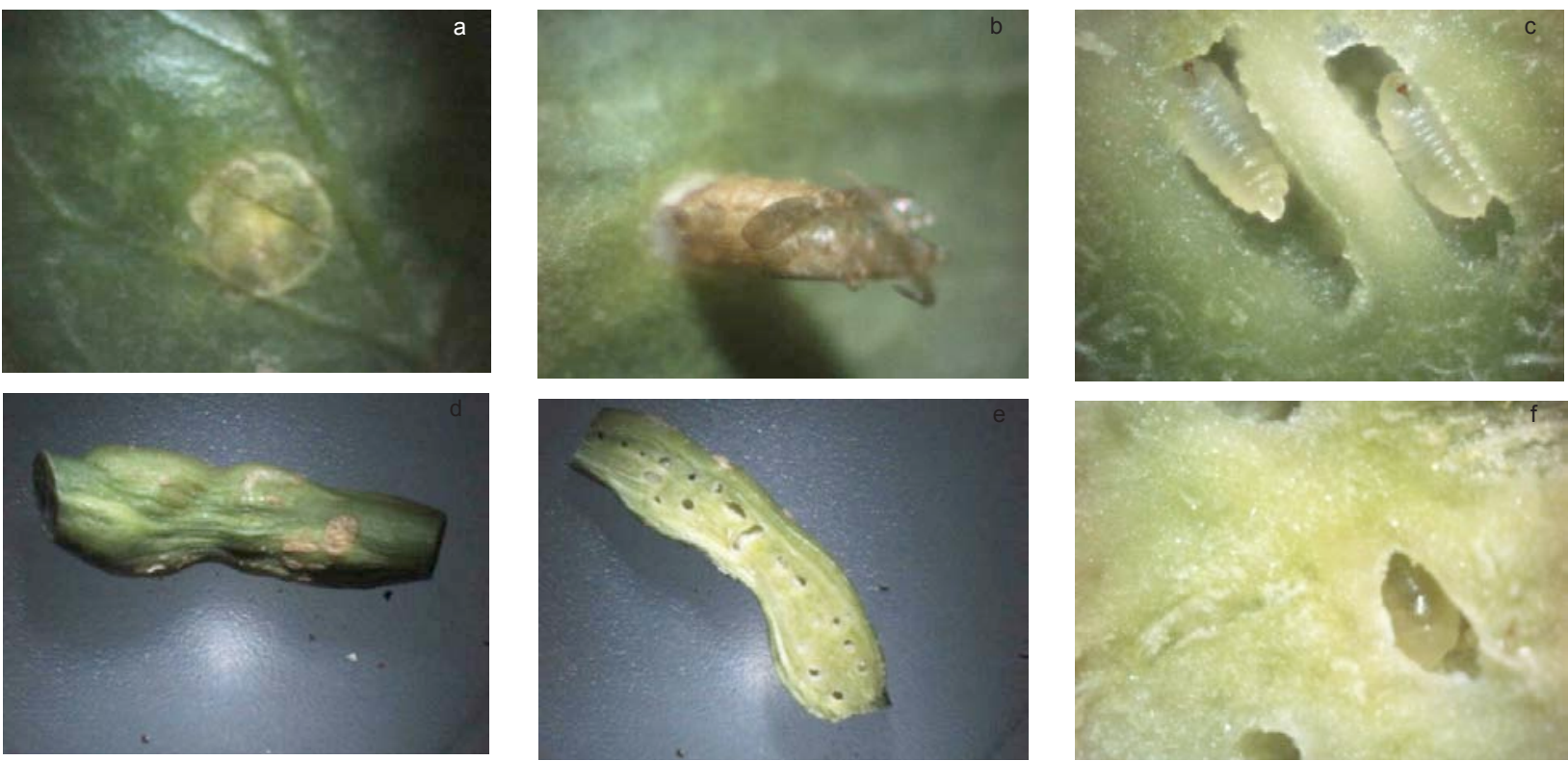

Image 1. Leaf gall and cecidomyiid larvae. (C) Moawia Mohamed

(a) leaf gall, (b) pupal skin on exit hole on underside of the leaf, (c) leaf gall section showing two chambers and cecidomyiid larvae, (d) stem galls, (e) longitudinal section through stem galls and (f) cecidomyiid larva in a stem gall
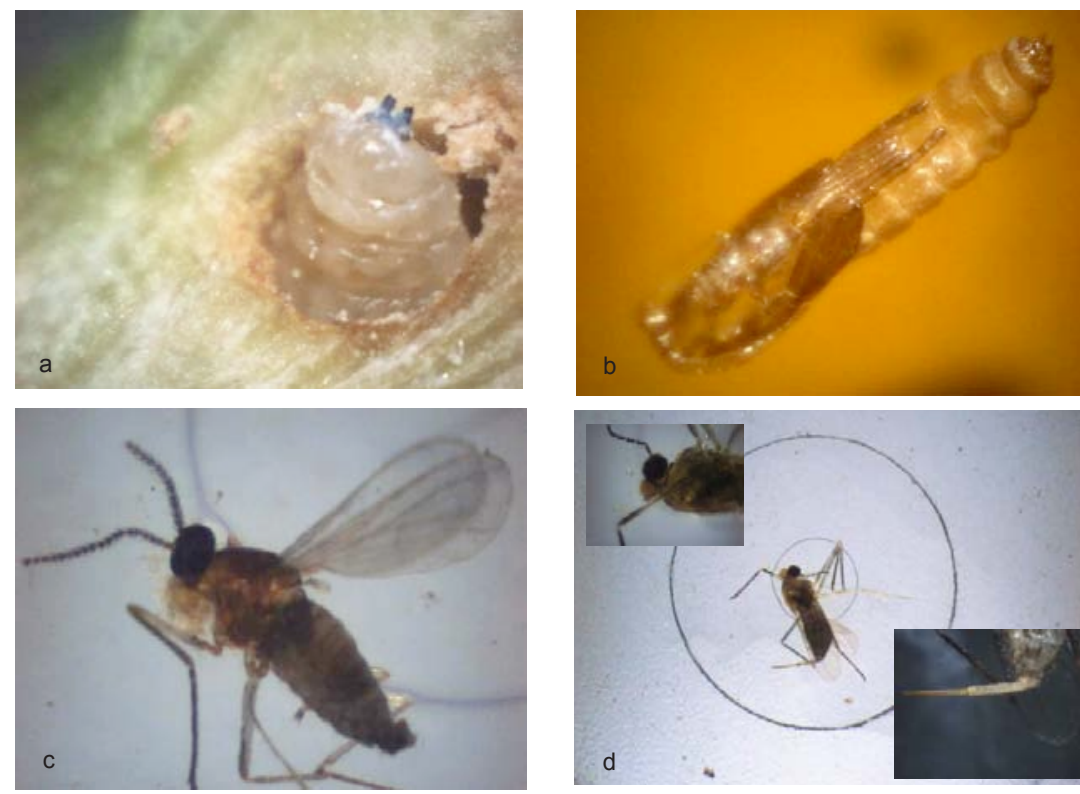

Image 2. Gall midge larva and adult. ( ) Moawia Mohamed

(a) developing gall midge larva, (b) gall midge pupa, (c) gall midge adult (male) and (d) gall midge adult (female). male and 2d, female). However, the parasites recovered in the present study key out to genus Platygaster Latreille (Rajmohana pers. comm. 15 June 2011).

Salvadora being important plant from medicinal point of view and its usefulness in ecorestoration of waste lands warrants detailed studies.

\section{REFERENCES}

Mani, M.S. (1973). Plant Galls of India. Macmillan, India, 354pp.

Rao, G., A.K. Nayak \& A. Chinchmalatpure (2003).

Salvadora persica: A life support species for salt affected black soils. Technical Bulletin No. 1 Published by Central Soil Salinity Research Institute (ICAR), Regional Research Station, Bharuch, Gujarat, 44pp.

Rao, S.N. (1951). Descriptions of two new genera and nine new species and one known species of gall midges from India (Itonodidae: Diptera) from India. Indian Journal 

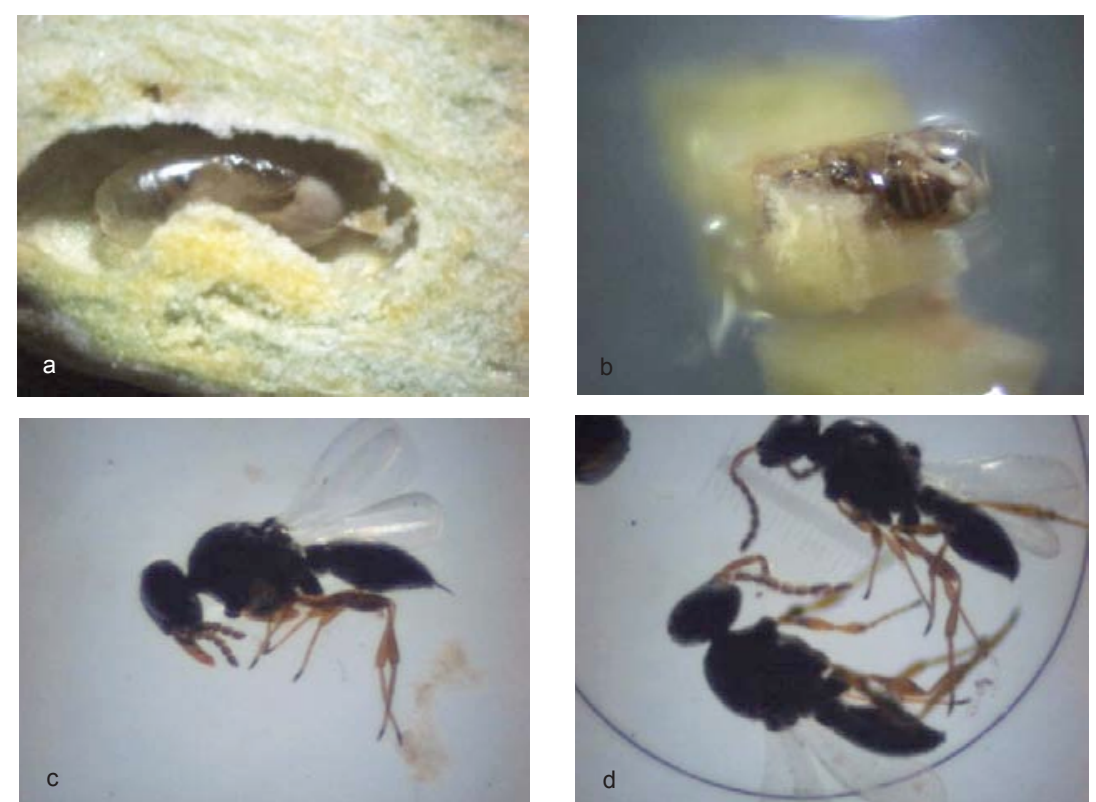

Figure 3. Parasitoid wasp. (c) Moawia Mohamed

(a) inside the midge larva, (b) inside the midge larva freed from the gall, (c) adult (female) and (d) adults (males). of Entomology 11: 109-127.

Rao, S.N. (1971). Gall midge damage to plants of medical importance in Marathwada. Marathwada University Journal of Science, Section B, Biological Sciences 10: 173-176.

Sharma, R.M., P.V. Joshi and M. Shindikar (2003). First Report on Plant Galls (Zoocecidia) from Mangrove Swamps of Vikhroli, Maharashtra. Zoos' Print Journal 18(10): 1217-1219

Sharma, R.M. (2009). Checklist of Indian Gall midges (Diptera: Cecidomyiidae). http://zsi.gov. in/checklist/Indian\%20Gall\%20 midges.pdf. Accessed on 13 July 2011. 